Bull. Chem. Soc. Ethiop. 2018, 32(1), 39-51.

ISSN 1011-3924

(C) 2018 Chemical Society of Ethiopia and The Authors

Printed in Ethiopia

DOI: https://dx.doi.org/10.4314/bcse.v32i1.4

\title{
REMOVAL OF HEAVY-METALS FROM WASTEWATER USING A HYDROUS ALUMINO-SILICATE MINERAL FROM KENYA
}

\author{
Enos W. Wambu ${ }^{1 *}$, Stephen Attahiru ${ }^{2}$, Paul M. Shiundu ${ }^{3}$ and John Wabomba ${ }^{2}$ \\ ${ }^{1}$ Department of Chemistry and Biochemistry, University of Eldoret, P.O. Box 1125-30100, \\ Eldoret, Kenya \\ ${ }^{2}$ Department of Chemistry, University of Nairobi, P.O. Box 30197-00100, Nairobi, Kenya \\ ${ }^{3}$ Department of Chemistry, Technical University of Kenya, P.O. Box 52428-00200, Nairobi, \\ Kenya
}

(Received December 5, 2014; Revised March 4, 2018; Accepted March 26, 2018)

\begin{abstract}
Heavy metals' discharge into the environment continues to pose grave concerns around the world. The efficacy of a hydrous alumino-silicate clay (AlSiM) coming obtained from some regions of Kenya to sorb heavy-metal ions from water has been evaluated in batch tests taking into account changes in adsorbent dose, $\mathrm{pH}$, contact time, and temperature. Complete metal removals, from water containing up to $66 \mathrm{mg} / \mathrm{L} \mathrm{of} \mathrm{Pb}$ (II) was achieved using this material at $\mathrm{pH}$ value of 5 over a temperature range of 289-333 K. The adsorption data fitted both the Langmuir and the Dubinin-Radushkevich isotherms with $\mathrm{R}^{2}>0.99$. The D-R adsorption energy $(-11.7$ $\mathrm{kJ} / \mathrm{mol}$ ) indicated that chemisorption was the primary reaction in the adsorption process and the derived $\Delta \mathrm{G}^{0}$ value $(-7.45 \mathrm{~kJ} / \mathrm{mol})$ was consistent with the spontaneity of the adsorption process. The kinetic analyses indicated a film-diffusion and surface-chemisorption controlled process. Verification of the initial results on heavy metalscontaining wastewaters obtained from a tannery and a leather processing industries revealed excellent adsorption efficacies of AlSiM for $\mathrm{Cr}^{3+}(99-100 \%), \mathrm{Fe}^{3+}(96-98 \%), \mathrm{Mn}^{2+}(85-97 \%)$ and $\mathrm{Zn}^{2+}(78-86 \%)$. The use of AlSiM as a plausible low-cost adsorbent for heavy-metal decontamination of industrial effluents has therefore been demonstrated.
\end{abstract}

KEY WORDS: Adsorption, Clays, Dubinin-Radushkevich, Heavy metals, Isotherms, Kinetics, Langmuir, Wastewater

\section{INTRODUCTION}

The presence of heavy metals in the environment pose serious public health and ecological concerns in many countries of the world [1,2]. Heavy metals are highly toxic and nondegradable. They easily accumulate and persist in water and soils in the environment from where they easily translate through food chains to humans [2]. Lead(II) pollution, in particular, poses a threat to biological systems. More so because lead(II) being the most toxic heavy metal pollutant after cadmium and mercury, it is more likely to be encountered in industrial effluents than either of the other two metals, as it is more versatile in its industrial applications than either of the two metals [3]. For this reason increasingly more stringent legislations are being placed upon industries to reduce metal discharge into the environment through industrial influents [4]. The industries are, as a consequence, required to implement more formidable effluent treatment practices in order to conform to required heavy metal standards.

Conventional technologies used in removal of metals' ions from wastewater include: coagulation, precipitation, contact precipitation, electro-coagulation, electrodialysis, reverse osmosis, solar distillation, adsorption, ion-exchange, and other membrane technologies. Most of these technologies are however either grossly inefficient or too expensive for small industries, such as those found in developing countries [5]. The use of more affordable alternative technologies has, for that matter, become the focus of environmental research, especially in the most recent years [6]. The media that is desired for easy and safe use for the removal of toxic metal ions from water should be affordable, potent, safe and usable in wide spectrum of

*Corresponding author. E-mail: wambuenos@yahoo.com

This work is licensed under the Creative Commons Attribution 4.0 International License 
wastewater conditions [7]. Clays and similar materials such as the one used in the present work have therefore attracted the scientific attention in the recent and past wastewater treatment protocols because of their ready availability, good adsorbent capacities, surface stability and ease of preparation for used in metal adsorption procedures [8].

On the other hand, lead(II) ions have one of the highest selectivity and affinity for soil surfaces when compared to those of most other metal pollutants [9]. Lead(II) typifies most of the metal pollutants in toxicity, environmental distribution and in potential uptake by natural adsorbents. $\mathrm{Pb}(\mathrm{II})$ is, for this reason, often used to evaluate new adsorbents for heavy metal removal from water [10].

In the present work, removal of lead(II) ions from water was used to assess the capacity of AlSiM to sorb pollutant metal species from wastewater. The criteria used was based on analyses of the effect of change in adsorbate concentration, $\mathrm{pH}$, temperature $(\mathrm{T})$, contact time $(t)$ and mass of adsorbent $(\mathrm{m})$ [7]. The kinetics and equilibrium characterization of the process was also performed. The results indicate that AlSiM could be used as a plausible inexpensive media for heavy metal-decontamination of wastewater streams.

\section{EXPERIMENTAL}

\section{Materials}

The adsorbent material (AlSiM) was obtained from its natural deposits in different zones of Kajiado County of Kenya. The material was washed in distilled water and dried at $383 \mathrm{~K}$ before it was pulverised using a hammer mill. The pulverized material was then screened through $0.25-$ $0.50 \mathrm{~mm}$ sieves. The chemical composition of the material, as previously determined [11], was composed of aluminosilicates $(44.4 \%)$, calcareous matter $(16.9 \%)$, ferric (hydr)oxides $(11.2 \%)$, exchangeable $\mathrm{Na}^{+}$and $\mathrm{K}^{+}$ions $(3.38 \%)$, titanium compounds $(2.31 \%)$ and traces of manganese $(0.14 \%)$ compounds. The rest of the material was found to be composed mainly of hygroscopic water and combustible soil organic matter. Analar grade reagents (Aldrich Chemical Company, USA) were used throughout this work. A stock solution of $\mathrm{Pb}$ (II) was prepared by dissolving $\mathrm{Pb}\left(\mathrm{NO}_{3}\right)_{3}$ in de-ionized water and the respective working solutions obtained from it by serial dilution with doubly de-ionized water.

\section{Instrumentation}

Adsorption tests were conducted by agitating batch adsorption mixture at preset experimental conditions as further indicated using a Maxmix Type 65800 Thermolyne Orbital Shaker. The temperature effect on the adsorption process was studied on a Boekel Scientific Incubator Model 133730. An SP8-15 Turnner Atomic Absorption Spectrophotometer was employed in determination of residual metals' concentration in the adsorbate solutions and in the analysis of the heavy-metal loading in test industrial effluents obtained from a leather industry and from a tannery. Finally, all pH measurements were made using a Fischer Scientific Combination $\mathrm{pH}$ Meter Model 15.

\section{Adsorption experiments}

Batch adsorption tests, unless otherwise specified, were conducted at room temperature $(298 \pm 0.5 \mathrm{~K})$ by agitating known mass $(1.0-10.0 \mathrm{~g})$ of AlSiM in metal ions' solutions of known concentrations $(50-14000 \mathrm{mg} / \mathrm{L})$. The preset rate of agitation was 180 cycles/min and the range of time intervals $(t)$ of agitation was 0-60 min. At the end of the selected agitation period, the mixture was centrifuged and the adsorbate concentrations in the supernatant solution measured by atomic absorption spectrophotometry (AAS). The amount, $q_{e}(\mathrm{mg} / \mathrm{g})$, and the percentage $(\%$ $q_{e}$ ) of adsorption of the metals ions were calculated from the respective expressions [12] as: 
$\mathrm{q}_{\mathrm{e}}=\left(\mathrm{C}_{\mathrm{o}}-\mathrm{C}_{\mathrm{e}}\right) \mathrm{V} / \mathrm{m}$

and

$\% \mathrm{q}_{\mathrm{e}}=100\left(\mathrm{C}_{\mathrm{o}}-\mathrm{C}_{\mathrm{e}}\right) / \mathrm{C}_{\mathrm{o}}$

where, $\mathrm{C}_{\mathrm{o}}$ and $\mathrm{C}_{\mathrm{e}}$ are the corresponding initial and equilibrium aqueous adsorbate concentrations $(\mathrm{mg} / \mathrm{L}), \mathrm{V}$ is the adsorption volume $(\mathrm{mL})$ and $\mathrm{m}$ is the mass of AlSiM $(\mathrm{g})$ in the batch mixture.

The efficacy of AlSiM to sorb $\mathrm{Pb}(\mathrm{II}), \mathrm{Zn}(\mathrm{II}), \mathrm{Cr}(\mathrm{III}), \mathrm{Fe}(\mathrm{III})$ and $\mathrm{Mn}(\mathrm{II})$ ions from industrial wastewaters was then investigated using wastewater streams from a tannery and a leather industries. The initial concentrations of $\mathrm{Pb}(\mathrm{II}), \mathrm{Zn}(\mathrm{II}), \mathrm{Cr}(\mathrm{III}), \mathrm{Fe}(\mathrm{III})$ and $\mathrm{Mn}$ (II) in the effluent streams was: $0.0,14.2,15.2,90.2$, and $7.1 \mathrm{mg} / \mathrm{L}$ for the tannery effluent and 13.4, 49.3, 13979, $1357,84.3$ and $11.1 \mathrm{mg} / \mathrm{L}$ for the leather industry effluent, respectively. To verify the efficacy of the adsorbent to sorb metal ions from the effluents, a dosage of $4 \mathrm{~g}$ of AlSiM to $80 \mathrm{~mL}$ of the industrial effluent was employed. All tests were conducted in duplicate.

\section{RESULTS AND DISCUSSION}

\section{Effect of mass of adsorbent}

The percentage removal of $\mathrm{Pb}$ (II) from solution increased with increasing batch adsorbent mass from just $56 \%$ at $50 \mathrm{~g} / \mathrm{L}$ adsorbent dosage to $99 \% \mathrm{~Pb}(\mathrm{II})$ removal from water, which could be achieved at AlSiM dosage of $200 \mathrm{~g} / \mathrm{L}$ of solution. In the initial stages, the amount of lead adsorbed increased linearly with respect to the adsorbent mass showing that the increase in mass of AlSiM multiplied the amount of available adsorbent sites at which $\mathrm{Pb}$ (II) ions could adsorb. It shows that AlSiM did not easily aggregate at high solid-water ratios, which led to near complete saturation of surface adsorbent sites in the material as desired for an efficacious adsorbent material.

\section{Effect of time of contact}

Figure 1 shows that the rate of removal of $\mathrm{Pb}(\mathrm{II})$ ions from water using $\mathrm{AlSiM}$ was, however, concentration-dependent.

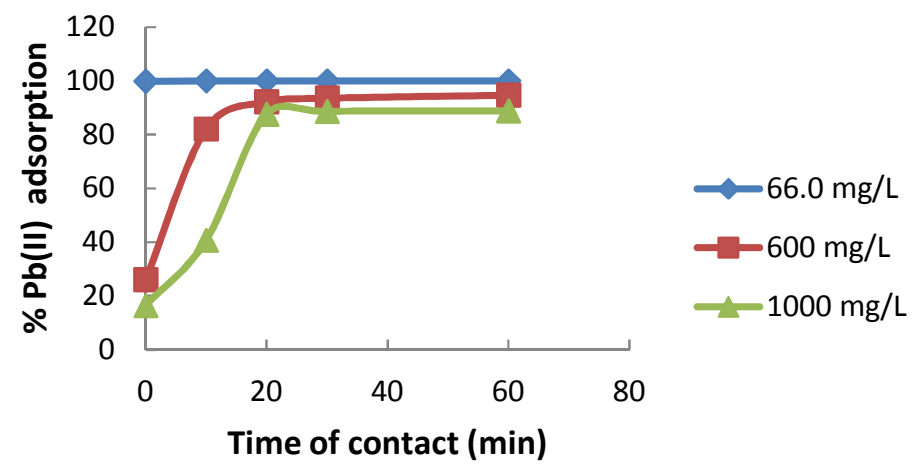

Figure 1. Effect of contact time on $\mathrm{Pb}$ (II) adsorption onto AlSiM (m $=150 \mathrm{~g} / \mathrm{L} ;\left[\mathrm{Pb}^{2+}\right]=66,600$, and $1000 \mathrm{mg} / \mathrm{L} ; \mathrm{T}=298 \mathrm{~K}$ )

Instantaneous and complete removal of $\mathrm{Pb}$ (II) ions from solution could be achieved at 66 $\mathrm{mg} / \mathrm{L}$ adsorbate concentrations. However, at $600 \mathrm{mg} / \mathrm{L}$ concentrations of the adsorbate, the 
percentage $\mathrm{Pb}(\mathrm{II})$ removal from water using $\mathrm{AlSiM}$ increased steadily with respect to increasing contact time and reached a maximum of about $93 \%$ after $30 \mathrm{~min}$. The initial curvature of the graph became convex to the time axis when higher initial $\mathrm{Pb}(\mathrm{II})$ concentrations of $1000 \mathrm{mg} / \mathrm{L}$ were employed. It showed that at the elevated initial concentration the adsorption rate increased progressively with increasing surface coverage of the mineral media with sorbed $\mathrm{Pb}(\mathrm{II})$ species and that surface saturation of AlSiM occurred after just about $20 \mathrm{~min}$.

This results showed that at $66 \mathrm{mg} / \mathrm{L}$ of initial adsorbate concentration, $\mathrm{Pb}$ (II) ions were rapidly sorbed from solution on exposed adsorbent sites in AlSiM. The progressive increase in the rate of adsorption [13], which was observed at higher adsorbate concentrations, indicated that the adsorption energy decreased gradually with increasing AlSiM surface coverage by the metal ions. Surface adsorption of $\mathrm{Pb}$ (II) ions onto AlSiM was therefore a heterogeneous process comprising gradual formation of surface monolayer of $\mathrm{Pb}$ (II) particles followed by a rapid accumulation of secondary layers of sorbed metal ions over the adsorbent surface.

\section{Effect of temperature}

The effect of temperature variation on $\mathrm{Pb}$ (II) immobilization onto AlSiM was then investigated. The adsorbate $\mathrm{Pb}(\mathrm{II})$ ions were completely removed from solutions at the $66 \mathrm{mg} / \mathrm{L}$ over the entire temperature range of $295-333 \mathrm{~K}$. At higher adsorbate concentrations $(1100 \mathrm{mg} / \mathrm{L})$, however, slightly lower removal efficiencies of $93-95 \%$ were recorded. There was a marginal increase in the efficacy of $\mathrm{Pb}$ (II) removal from $93 \%$ to $95 \%$ when the equilibration temperature was raised from 298 to $348 \mathrm{~K}$. It showed that $\mathrm{Pb}$ (II) uptake by AlSiM was a chemisorption endothermic process. There was a stepwise change in the adsorption efficiency of the media with increasing temperature, which was indicative of thermodynamic heterogeneity in the adsorption process [14]. The increased in percentage adsorption that was recorded in temperature range of $323-333 \mathrm{~K}$ showed that thermal activation increased $\mathrm{Pb}$ (II) uptake by AlSiM. This further affirmed that chemisorption processes played a primary role in aqueous $\mathrm{Pb}$ (II) uptake by AlSiM.

\section{Effect of $p H$}

Figure 2 shows the effect of change in solution $\mathrm{pH}$ on $\mathrm{Pb}$ (II) uptake by AlSiM. The percentage $\mathrm{Pb}(\mathrm{II})$ adsorption onto AlSiM increased with increasing $\mathrm{pH}$ and complete metal removal from water was achieved in $\mathrm{pH}$ range of $4-5.5$.

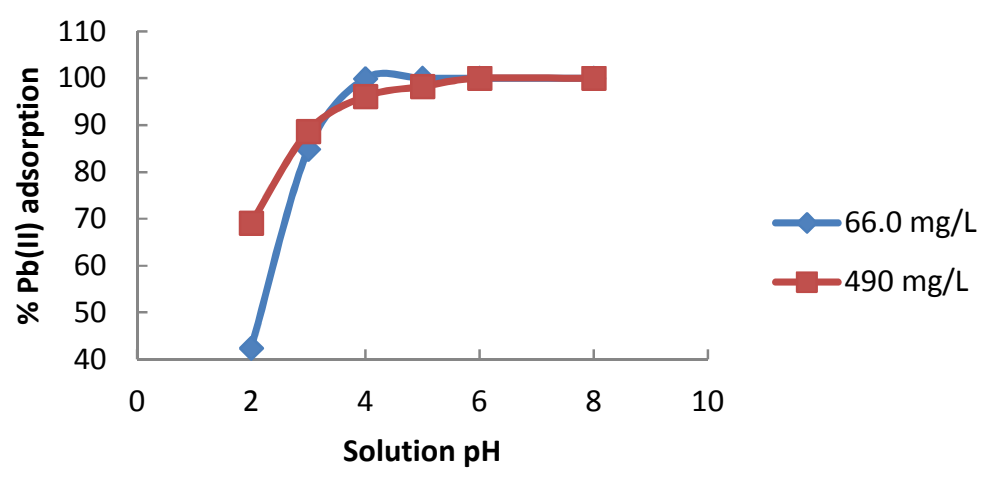

Figure 2. Effect of $\mathrm{pH}$ on $\mathrm{Pb}(\mathrm{II})$ adsorption onto AlSiM $\left(\mathrm{m}=150 \mathrm{~g} / \mathrm{L} ; \mathrm{t}=60 \mathrm{~min} ;\left[\mathrm{Pb}^{2+}\right]=66.0\right.$ $\mathrm{mg} / \mathrm{L}, 490 \mathrm{mg} / \mathrm{L} ; \mathrm{T}=298 \pm 0.5 \mathrm{~K})$. 
Soil surfaces normally develop amphoteric hydroxyl groups, which ionize in an aqueous medium according to the following reactions as [15]:

$$
\begin{aligned}
& \mathrm{SOH}+\mathrm{H}^{+} \stackrel{\mathrm{pH}<\mathrm{pHznc}}{=} \mathrm{SOH}_{2}^{+} \\
& \text {and } \\
& \mathrm{SOH}+\mathrm{OH}^{-} \stackrel{\mathrm{pH}>\mathrm{pHznc} \longrightarrow \mathrm{SO}^{-}+\mathrm{H}_{2} \mathrm{O}}{=}
\end{aligned}
$$

where, $\mathrm{SOH}, \mathrm{SOH}_{2}^{+}$and $\mathrm{SO}^{-}$are neutral, protonated and ionized surface hydroxyl functional groups, respectively. The protonated, $\mathrm{SOH}_{2}^{+}$, surfaces dominate at $\mathrm{pH}$ values less than 1.5 and neutral soil surfaces, $\mathrm{SOH}$, in the $\mathrm{pH}$ range of 1.5-3.5. Ionization of neutral sites into high affinity $\mathrm{SO}^{-}$surfaces is favored at $\mathrm{pH}$ values greater than 3.5 [16]. The optimum sequestration of $\mathrm{Pb}(\mathrm{II})$ ions by AlSiM surfaces, which was observed in this range of $\mathrm{pH}$ values in current work, indicated that ionized, $\mathrm{SO}^{-}$, surface groups were the dominant reactive sites for $\mathrm{Pb}(\mathrm{II})$ immobilization into AlSiM surfaces. This would explain apparent existence of strong chemisorptions interactions postulated in the preceding sections of the current work.

\section{Adsorption isotherms}

To clarify the adsorption processes and gain further insight into the $\mathrm{Pb}$ (II) adsorption onto AlSiM, equilibrium experiments were conducted at different adsorbate concentrations while maintaining the other parameters constant. The results were used to construct adsorption isotherms and to characterize the equilibrium uptake of $\mathrm{Pb}(\mathrm{II})$ by AlSiM. The general adsorption isotherm for $\mathrm{Pb}(\mathrm{II})$ uptake by AlSiM surfaces, which is depicted in Figure 3, was found to be a typical high affinity type two or $\mathrm{H} 2$ isotherm [13]. It showed that AlSiM had such high affinities for $\mathrm{Pb}(\mathrm{II})$ ions that at concentrations less than $158 \mathrm{mg} / \mathrm{L}, \mathrm{Pb}$ (II) ions were completely removed from solution and the initial part of the isotherm curve ran perpendicular to the adsorbate concentration axis.

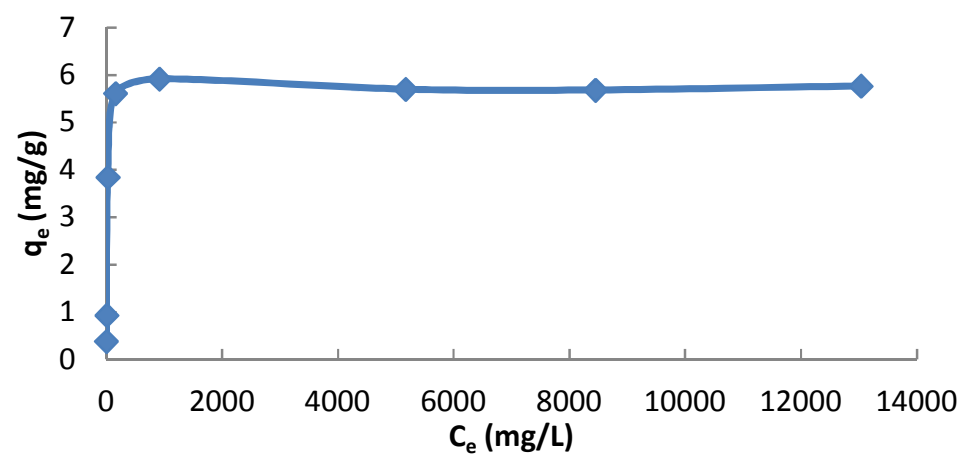

Figure 3. General adsorption isotherm for $\mathrm{Pb}(\mathrm{II})$ adsorption onto AlSiM $(\mathrm{m}=150 \mathrm{~g} / \mathrm{L} ; \mathrm{t}=60$ $\min ; \mathrm{T}=298 \pm 0.5 \mathrm{~K})$.

In order to validate existence of this high affinity Langmuir-type sorptive sites for $\mathrm{Pb}(\mathrm{II})$ ions in AlSiM surfaces, the equilibrium adsorption data was appropriated to the Langmuir adsorption isotherm in linearized form as [17]:

$1 / \mathrm{qe}=1 /\left(\mathrm{q}_{\mathrm{m}} \mathrm{k}_{\mathrm{L}}\right) \mathrm{C}_{\mathrm{e}}+1 /\left(\mathrm{q}_{\mathrm{m}}\right)$ 
where, $q_{m}$ and $k_{L}$ are Langmuir adsorption capacity of AlSiM $(\mathrm{mg} / \mathrm{g})$, and the Langmuir equilibrium constant $(\mathrm{L} / \mathrm{g})$, respectively. As illustrated in Figure $4, \mathrm{~Pb}$ (II) adsorption onto AlSiM fitted the Langmuir model with high $\mathrm{R}^{2}$ values of 0.992 .

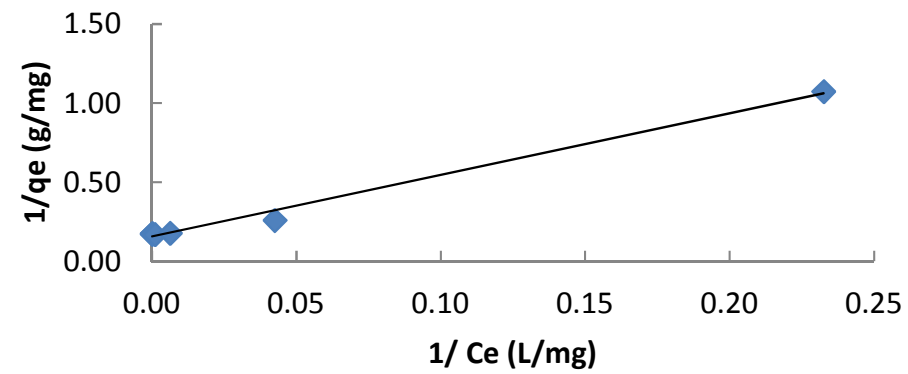

Figure 4. Langmuir adsorption isotherm for $\mathrm{Pb}(\mathrm{II})$ adsorption onto $\operatorname{AlSiM}(\mathrm{pH}=4.5 ; \mathrm{m}=150$ $\mathrm{g} / \mathrm{L} ; \mathrm{t}=60 \mathrm{~min} ; \mathrm{T}=298 \mathrm{~K}$ ).

The adsorption process could therefore be described by this empirical model as is normally the case for chemisorption Langmuir adsorption processes. The shape of Langmuir plot was further evaluated using the dimensionless Langmuir parameter, $\mathrm{R}_{\mathrm{L}}$, which is defined as [18]:

$\mathrm{R}_{\mathrm{L}}=1 /\left(1+\mathrm{k}_{\mathrm{L}} \mathrm{C}_{0}\right)$

where, $\mathrm{C}_{0}$ is the initial adsorbate concentration $(\mathrm{mg} / \mathrm{L})$ and $\mathrm{k}_{\mathrm{L}}$ is the Langmuir isotherm constant. The nature of the Langmuir adsorption process is classified based on the value of $R_{L}$ parameter as favorable if $R_{L}<1$; unfavorable for $R_{L}>1$; linear if $R_{L}=1$ and irreversible when $R_{L}=0$. As per the current work, the value of $R_{L}$ was 0.0107 , which indicated a favourable adsorption process. It was noted that values of $\mathrm{R}_{\mathrm{L}}$ decreased with increasing adsorbate concentration indicating that $\mathrm{Pb}(\mathrm{II})$ adsorption was more favourable at higher concentrations than at lower adsorbate concentrations.

To determine the adsorption energy and obtain additional elucidation of the adsorption mechanism for this process, the adsorption data were further validated based on the DubininRadushkevitch (D-R) isotherm in the form [19]:

$\ln \mathrm{q}_{\mathrm{e}}=\ln \mathrm{q}_{\mathrm{m}}-\beta \varepsilon^{2}$

where, $\mathrm{q}_{\mathrm{m}}$ represents the maximum sorption capacity of AlSiM, $\beta$ is a D-R constant and $\varepsilon$ is the Polanyi sorption potential [20]. The Polanyi potential is related to equilibrium concentration, $C_{e}$, by the expression:

$\varepsilon=\mathrm{RT} \ln (1+(1 / \mathrm{Ce}))$

where, $\mathrm{R}$ is the gas constant $8.314 \mathrm{~J} /(\mathrm{mol} \mathrm{K}), \mathrm{T}$ is temperature $(\mathrm{K})$. Additionally the value of $\varepsilon$ is related to adsorption energy, E, by:

$\mathrm{E}=(-2 \beta)^{-1 / 2}$

As depicted in Figure 5, the equilibrium data for $\mathrm{Pb}(\mathrm{II})$ adsorption onto AlSiM fitted the D-R isotherm model with $\mathrm{R}^{2}$ values of 0.991 . $\mathrm{Pb}$ (II) adsorption onto AlSiM could therefore be described by this model as well. The D-R adsorption capacity for lead(II) adsorption onto AlSiM $(5.75 \mathrm{mg} / \mathrm{g})$ was consistent with experimental values $(5.93 \mathrm{mg} / \mathrm{g})$ and with the Langmuir adsorption capacity $(6.33 \mathrm{mg} / \mathrm{g})$ even though the latter was somewhat higher. 


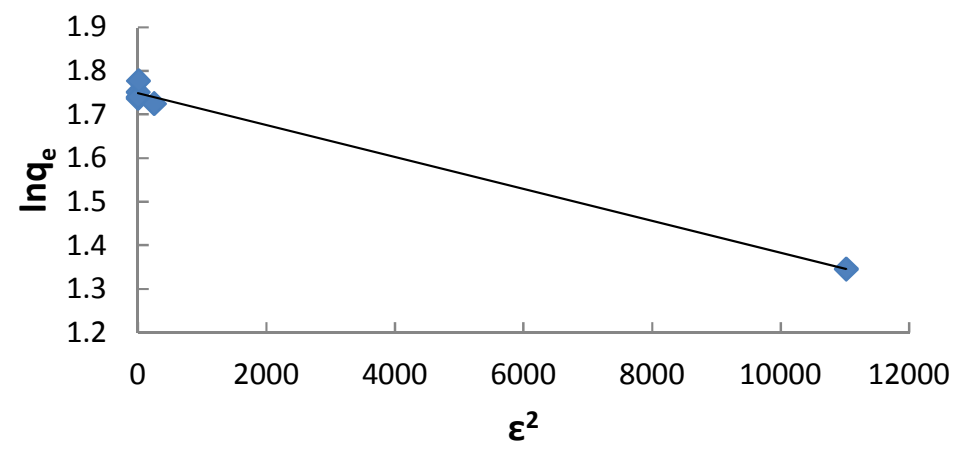

Figure 5. Dubinin-Radushkevich (D-R) isotherm $\mathrm{Pb}(\mathrm{II})$ adsorption onto AlSiM $(\mathrm{pH}=4.5 ; \mathrm{m}=$ $3.0 \mathrm{~g} / 20 \mathrm{~mL} ; \mathrm{t}=60 \mathrm{~min} ; \mathrm{T}=298 \mathrm{~K})$.

The small variation in the lead(II) adsorption capacities of AlSiM as obtained from the two isotherms was expected because of different underlying theoretical assumptions upon which each of the isotherms is based. The D-R equation applies to a more general case than the Langmuir model because the D-R equation does not assume a homogeneous adsorption and it does not preclude interactions between adsorbed and incoming particles [4], which are postulated in the present work.

The magnitude of D-R adsorption energy, $E$, indicates the dominant type of adsorption. In general, D-R adsorption energies of $8-16 \mathrm{~kJ} / \mathrm{mol}$ indicate existence of chemisorption processes whereas values of $\mathrm{E}$ values less than $8 \mathrm{~kJ} / \mathrm{mol}$ show that physisorption is the dominant process. The value of $\mathrm{E}$ in the current study was $-11.7 \mathrm{~kJ} / \mathrm{mol}$ confirming that $\mathrm{Pb}$ (II) uptake by AlSiM was a surface chemisorption process.

\section{Comparisons with other adsorbents}

The current Langmuir adsorption constants and optimum operating $\mathrm{pH}$, temperature and time of contact for $\mathrm{Pb}(\mathrm{II})$ adsorption onto AlSiM were compared with those of similar low-cost adsorbents, which have recently been studied for $\mathrm{Pb}$ (II) sequestration from water. The results of these comparisons are depicted in Table 1.

Sample ion-exchange resins showed highest mean $\mathrm{Pb}(\mathrm{II})$ removal capacities $(116 \mathrm{mg} / \mathrm{g}$ ) followed by bio-sorbents $(53.3 \mathrm{mg} / \mathrm{g})$ and activated carbons $(27.7 \mathrm{mg} / \mathrm{g})$. With the exception of a manganese oxide ore [32], soil adsorbents had mean $\mathrm{Pb}(\mathrm{II})$ adsorption capacities of $13.1 \mathrm{mg} / \mathrm{g}$. Lead(II) uptake by activated carbons was found to be strongly $\mathrm{pH}$-controlled; the mean adsorption capacities at $\mathrm{pH}$ values greater than 5 was $54.4 \mathrm{mg} / \mathrm{g}$ but a paltry mean value of 2.0 $\mathrm{mg} / \mathrm{g}$ was indicated for $\mathrm{pH}$ values less than 5 . The table also shows that optimum $\mathrm{Pb}(\mathrm{II})$ adsorption onto mineral adsorbents occur in the $\mathrm{pH}$ range between 5-6, which was consistent with the results of the current work. This strong $\mathrm{pH}$ influence on $\mathrm{Pb}$ (II) adsorption from water could be associated with changes in $\mathrm{Pb}$ (II) speciation, which control the affinity of aqueous $\mathrm{Pb}$ (II) species for charged mineral surface [33].

The differences in the adsorbent capacities of different materials to sorb metal ions from water arise from differences of the mineral media in physicochemical characteristics and from variations in experimental conditions used by the researchers [16]. In the current work, complete removal of lead(II) from solution was achieved when $\mathrm{Pb}(\mathrm{II})$ concentrations of $66 \mathrm{mg} / \mathrm{L}$ was used. Even though the adsorption capacity of AlSiM was not the highest one, at least with regard to the other adsorbents referred to in Table 1, the present results demonstrated that AlSiM 
could be used to sorb aqueous $\mathrm{Pb}$ (II) from water, as from an economic perspective, the adsorbent can be obtained easily in large quantities from its natural deposits.

Table 1. Comparison of Langmuir constants for $\mathrm{Pb}$ (II) adsorption onto AlSiM to those of other common adsorbents.

\begin{tabular}{|c|c|c|c|c|c|c|c|}
\hline \multirow[t]{2}{*}{ Adsorbent } & \multicolumn{3}{|c|}{ Conditions } & \multicolumn{3}{|c|}{ Langmuir constants } & \multirow[t]{2}{*}{ Ref. } \\
\hline & $\mathrm{pH}$ & (K) & $t(\min )$ & $\mathrm{q}_{\mathrm{m}}$ & $\mathrm{k}_{\mathrm{L}}$ & $\mathrm{R}^{2}$ & \\
\hline \multicolumn{8}{|l|}{ Low-cost biosorbents } \\
\hline Sugar beet pulp waste & 5.5 & 293 & 120 & 73.67 & & 0.936 & {$[21]$} \\
\hline Citrobacter strain MCM B-181 & 6 & 298 & 30 & 58.78 & 0.11 & 0.99 & [22] \\
\hline Waste beer yeast by-product & 5 & 301 & 15 & 55 & 0.0883 & 0.9975 & [23] \\
\hline Mansonia wood sawdust & 6 & 299 & 240 & 51.81 & 0.1852 & 0.9998 & [24] \\
\hline Grape stalk waste & 5.5 & 298 & 120 & 49.89 & 0.0004 & 0.959 & [12] \\
\hline Sphagnum moss peat & 6.0 & 313 & 240 & 30.8 & 0.382 & 0.984 & [25] \\
\hline Seaweed Sargassum filipendula & 4 & 303 & 1440 & 1.35 & 20.2 & 0.9894 & [26] \\
\hline \multicolumn{8}{|l|}{ Commercial and low-cost activated carbons } \\
\hline Activated carbon (Cola edulis) & 6 & 308 & 120 & 100 & 0.00782 & 0.96 & [27] \\
\hline Commercial activated carbon & 7 & $296-308$ & 4320 & 54.945 & 0.938 & 0.996 & [28] \\
\hline Activated carbon (Aucoumea klaineana) & 6 & 308 & 120 & 50 & 0.0234 & 0.99 & [27] \\
\hline Activated carbon (Pentaclethra macrophylla) & 6 & 308 & 120 & 33.3 & 0.0435 & 0.85 & [27] \\
\hline Activated carbon from cashew nut shells & 6.5 & 303 & 30 & 28.98 & 0.0029 & 0.922 & [29] \\
\hline Activated carbons from coconut & 4 & 313 & $\mathrm{Ng}$ & 4.56 & 6000 & 0.9765 & [30] \\
\hline Activated carbons from seed hull of pa & 4 & 333 & $\mathrm{Ng}$ & 3.77 & 4610 & 0.9763 & [30] \\
\hline Commercial activated carbon (CAC) & 7 & & 120 & 0.2191 & 0.2751 & 0.996 & [31] \\
\hline Activated periwinkle shell carbon (PSC) & 7 & & 120 & 0.0558 & 0.1430 & 0.972 & [31] \\
\hline \multicolumn{8}{|l|}{ Commercial and low-cost mineral adsorbents } \\
\hline Low grade manganese ore & 5.25 & 300 & 240 & 142.85 & 0.005 & 0.976 & [32] \\
\hline Nitrogen grafted silica & $5.5-6.0$ & 293 & 300 & 38.07 & & 0.9993 & [33] \\
\hline Li-bentonites & 5 & 297 & 60 & 26 & 37.5 & 0.99 & [34] \\
\hline Na-bentonies & 5 & 297 & 60 & 18 & 4.9 & 0.93 & [34] \\
\hline Mg-bentonites & 5 & 297 & 60 & 14 & 68.13 & 0.99 & [34] \\
\hline Ca-bento & 5 & 297 & 60 & 13 & 67.2 & 0.95 & [34] \\
\hline Al-bentonites & 5 & 297 & 60 & 12 & 39.38 & 0.90 & [34] \\
\hline Fe-bentonites & 5 & 297 & 60 & 11 & 42.43 & 0.77 & [34] \\
\hline Clayey, mixed siliceous soil & 5.75 & 298 & 60 & 10.888 & 0.0101 & 0.98 & [35] \\
\hline K-bentonite & 5 & 297 & 60 & 8 & 109.9 & 0.99 & [34] \\
\hline $\begin{array}{l}\text { Hydrous alumino-silicate mineral adsorbent } \\
\text { from Kenya (AlSiM) }\end{array}$ & 5 & 297 & 60 & 6.33 & 1.63 & 0.992 & $\begin{array}{c}\text { Present } \\
\text { work }\end{array}$ \\
\hline Clayey, kaolinitic soil & 5.42 & 298 & 60 & 6.189 & 0.2444 & 0.98 & [36] \\
\hline Unmodified silica & $5.5-6.0$ & 293 & 300 & 3.9 & & 0.9987 & [33] \\
\hline Calcareous soil & 6 & 313 & 60 & 2.34 & 0.666 & 0.918 & [37] \\
\hline \multicolumn{8}{|l|}{ Commercial and low-cost ion-exchange resins } \\
\hline Salicyclic aci-formaldehyde resorcinol & & 298 & 360 & 169.32 & & 0.9892 & [38] \\
\hline Salicyclic acid-formaldehyde chatechol & & 298 & 360 & 143.23 & & 0.9974 & [38] \\
\hline Vanolia tannin resin & & & 360 & 138.276 & & 0.999 & [39] \\
\hline Chitosan & 4.5 & 293 & 14 days & 115.51 & 1.307 & 0.914 & [40] \\
\hline $\mathrm{MnO}_{2}$ Loaded-Resin & & 296 & 4320 & 80.64 & & 0.991 & [41] \\
\hline Thiacalix(4)arene loaded resin & & & & 47.9 & 0.0144 & 0.996 & [42] \\
\hline
\end{tabular}

\section{Adsorption kinetics}

The time-dependent $\mathrm{Pb}(\mathrm{II})$ adsorption onto AlSiM was analyzed using Lagergren's pseudo-firstorder model [43] (Figure 6) and Ho's pseudo-second order kinetic model [44] (Figure 7). The pseudo-first order rate equation was used in the form:

$\ln \left(\mathrm{q}_{\mathrm{e}}-\mathrm{q}_{\mathrm{t}}\right)=\ln \mathrm{q}_{\mathrm{e}}-\mathrm{k}_{1} \mathrm{t}$ 
where, $\mathrm{q}_{\mathrm{t}}$ and $\mathrm{q}_{\mathrm{e}}(\mathrm{mg} / \mathrm{g})$ are metal adsorptions at equilibrium $(\mathrm{mg} / \mathrm{g})$ and at time, $\mathrm{t},(\mathrm{min})$, respectively, and $\mathrm{k}_{1}$ is the rate constant (per min) obtainable from a plot of $\ln (\mathrm{qe}-\mathrm{qt}$ ) versus $\mathrm{t}$.

The form of pseudo-second order equation used was:

$$
\mathrm{t} / \mathrm{q}_{\mathrm{t}}=1 /\left(\mathrm{k}_{2} \mathrm{q}_{\mathrm{e}}{ }^{2}\right)+\left(1 / \mathrm{q}_{\mathrm{e}}\right) \mathrm{t}
$$

where, $\mathrm{k}_{2}$ is the second-order rate constant and, $\mathrm{q}_{\mathrm{e}}$ being adsorbent equilibrium capacity. A plot of $t / q_{t}$ versus $t$ should be linear from which both $k_{2}$ and $q_{e}$ can be determined.

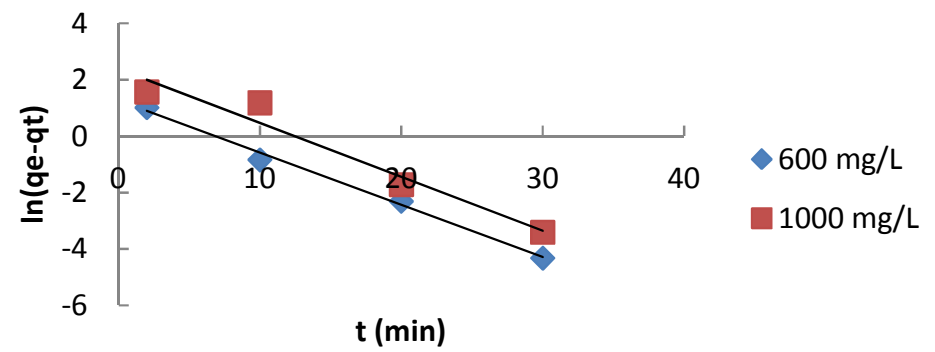

Figure 6. Lagergren's pseudo-first-order kinetics model for $\mathrm{Pb}(\mathrm{II})$ adsorption onto AlSiM $(\mathrm{pH}=$ $4.5 ; \mathrm{m}=150 \mathrm{~g} / \mathrm{L} ;\left[\mathrm{Pb}^{2+}\right]=600 \mathrm{~m} / \mathrm{L}$ and $\left.1000 \mathrm{mg} / \mathrm{L} ; \mathrm{T}=298 \mathrm{~K}\right)$.

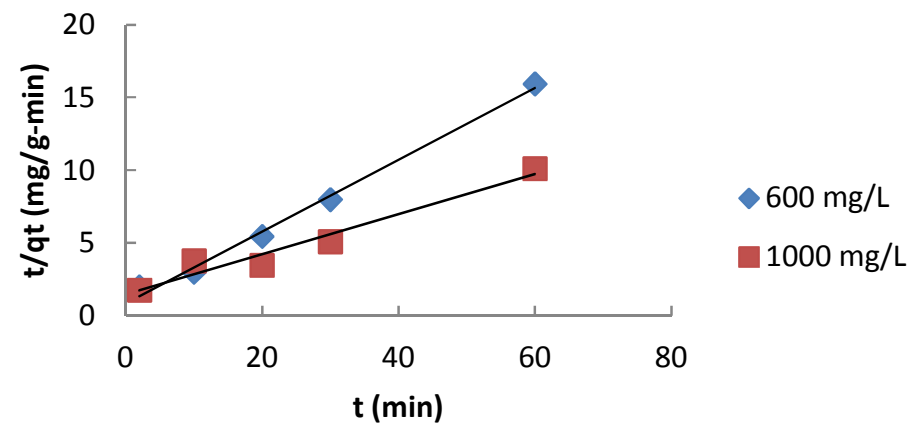

Figure 7. Lagergren's pseudo-second-order kinetics model for $\mathrm{Pb}(\mathrm{II})$ adsorption onto AlSiM ( $\mathrm{pH}$ $=4.5 ; \mathrm{m}=150 \mathrm{~g} / \mathrm{L} ;\left[\mathrm{Pb}^{2+}\right]=600 \mathrm{mg} / \mathrm{L}$ and $\left.1000 \mathrm{mg} / \mathrm{L} ; \mathrm{T}=298 \mathrm{~K}\right)$.

The resulting kinetics data for lead(II) adsorption are depicted in Table 2.

Table 2. Rate coefficients for adsorption of $\mathrm{Pb}(\mathrm{II})$ onto AlSiM.

\begin{tabular}{|l|c|c|}
\hline$\left[\mathrm{Pb}^{2+}\right](\mathrm{mg} / \mathrm{L}$ & 600 & 1000 \\
\hline $\mathrm{q}_{\mathrm{e}, \exp }(\mathrm{mg} / \mathrm{g})$ & 3.767 & 5.933 \\
\hline Lagergren's pseudo-first order kinetics & \multicolumn{2}{|c|}{} \\
\hline $\mathrm{k}_{1}\left(\mathrm{~min}^{-1}\right)$ & 0.174 & 0.178 \\
\hline $\mathrm{q}_{\mathrm{e}}$ & 2.748 & 8.012 \\
\hline $\mathrm{R}^{2}$ & 0.996 & 0.933 \\
\hline Ho's pseudo-second order kinetics & \multicolumn{2}{|l|}{} \\
\hline $\mathrm{k}_{2}(\mathrm{~g} / \mathrm{mg}-\mathrm{min})$ & 0.0704 & 0.0127 \\
\hline $\mathrm{h}_{\mathrm{o}}(\mathrm{mg} / \mathrm{g}-\mathrm{min})$ & 1.164 & 0.677 \\
\hline $\mathrm{q}_{\mathrm{e}, \text { calc }}(\mathrm{mg} / \mathrm{g})$ & 4.065 & 7.299 \\
\hline $\mathrm{R}^{2}$ & 0.993 & 0.954 \\
\hline
\end{tabular}

Bull. Chem. Soc. Ethiop. 2018, 32(1) 
The adsorption data fitted the pseudo-first order and the pseudo-second order kinetics models with $\mathrm{R}^{2}$ values of $0.933-0.996$ and $0.954-0.993$, respectively. Kinetics of adsorption of $\mathrm{Pb}$ (II) ions onto AlSiM could therefore be described by these models. Both the pseudo-first order and the pseudo-second order models did not, however, give good approximations of experimental adsorption capacities of $\mathrm{AlSiM}$ for aqueous $\mathrm{Pb}$ (II) ions. Nevertheless, adherence of $\mathrm{Pb}$ (II) adsorption data to first order kinetics [30] and to second order kinetics [45] have previously been reported in the literature. The concurrent conformity of the metal adsorption data to the two models, which has also been reported elsewhere in the literature [46], indicated that film diffusion and surface chemisorption were the rate determining steps in the adsorption protocol.

Adsorption thermodynamics

The Gibbs free energy of adsorption, $\Delta G^{0}$, is normally expressed in terms of the thermodynamic equilibrium constant, $K_{C}=q_{e} / C_{e}$ as:

$\Delta G^{0}=-R T \ln K_{c}$

The adsorption enthalpy, $\Delta H^{0}$, and the adsorption entropy, $\Delta S^{0}$, can then be obtained from van't Hoff's plots as:

$\Delta G^{0}=\Delta H^{0}-T \Delta S^{0}$

The derived value for $\Delta \mathrm{G}^{0}$ for lead(II) adsorption onto AlSiM surfaces averaged $+3.64 \mathrm{~kJ} / \mathrm{mol}$ at $\mathrm{Pb}$ (II) concentration of $47 \mathrm{mg} / \mathrm{L}$ and $-7.45 \mathrm{~kJ} / \mathrm{mol}$ at $362 \mathrm{mg} / \mathrm{L}$ of initial $\mathrm{Pb}$ (II) ions. This indicated that $\mathrm{Pb}(\mathrm{II})$ adsorption onto $\mathrm{AlSiM}$ was more favorable at higher adsorbate concentrations than at the lower concentrations as also postulated in the earlier parts of the current work. Accordingly the values of $\Delta \mathrm{H}^{0}$ and $\Delta \mathrm{S}^{0}$ were $-5.21 \mathrm{~kJ} / \mathrm{mol}$ and $+0.0067 \mathrm{~kJ} / \mathrm{mol} / \mathrm{K}$, respectively, as expected for an exothermic chemisorption process. Positive values of $\Delta \mathrm{S}^{0}$ indicated envisaged disruptions in the ordered electrical double layer at the clay surface as progressively more $\mathrm{Pb}(\mathrm{II})$ ions adsorbed on the AlSiM surfaces.

Efficacy of AlSiM to sorb selected metal ions from real industrial effluents

The efficacy of AlSiM to remove various heavy metal ions from contaminated wastewater was tested using untreated aqueous waste streams from a tannery and from a leather industry from Nairobi, Kenya. Whereas $\mathrm{Pb}(\mathrm{II})$ removal from solution using AlSiM was just about $46 \%$ as depicted in Figure 8, the removal of the other metal ions, which included: $\mathrm{Zn}^{2+}, \mathrm{Cr}^{3+}, \mathrm{Fe}^{3+}$ and $\mathrm{Mn}^{2+}$, from the aqueous streams ranged from 80 to $100 \%$.

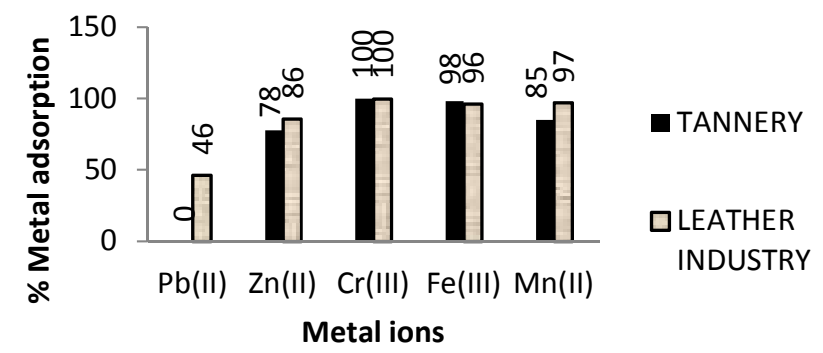

Figure 8. Efficacy of AlSiM to sorb metal ions from industrial effluents $(\mathrm{m}=4.0 \mathrm{~g}$ per $80 \mathrm{~mL}$; $\mathrm{T}$ $=298 \mathrm{~K}, \mathrm{t}=20 \mathrm{~min}$ ). 
In general, adsorption efficacy of AlSiM for different metal ions from the wastewater decreased in the order: $\mathrm{Cr}^{3+}>\mathrm{Fe}^{3+}>\mathrm{Mn}^{2+}>\mathrm{Zn}^{2+}>\mathrm{Pb}^{2+}$. It showed that the trivalent metal ions were more strongly removed from the industrial effluents using this adsorbent than the divalent ions. It showed that the cation with greater charge had greater affinity for AlSiM surfaces than those with the lesser charge. This would be consistent with electrostatic chemisorption processes, which have been postulated in the earlier sections of this work. However, there were slight variations between the heavy metals' removal efficiencies of the proposed media between the two types of wastewater tested. This variation was expected due to the differences in the background chemistry of the wastewater effluents from the two different industries.

\section{CONCLUSIONS}

The present work was designed to assess the efficacy of a hydrous alumino-silicate clay obtained from parts of the Kenyan rift valley to sorb heavy metal ions from wastewater. The capacity of the media to remove metals' ions from solution was found to be strongly controlled by solution $\mathrm{pH}$, temperature, adsorbent dosage, contact time and adsorbate concentration. Complete removal of metal ions from water containing up to $66 \mathrm{mg} / \mathrm{L}$ of $\mathrm{Pb}$ (II) ions could be achieved over a temperature spectrum of 289-333 K using this media. The experimental data was validated using the Langmuir and Dubinin-Radushkevich isotherms and the derived Langmuir and D-R lead(II) adsorption capacities $(\mathrm{mg} / \mathrm{g}$ ) of $\mathrm{AlSiM}$ were 6.33 and 5.75, respectively. The D-R corresponding adsorption energy was $-11.7 \mathrm{~kJ} / \mathrm{mol}$, which showed that the metal adsorption onto AlSiM was chemical in nature. The values of derived $\Delta G^{0}$ $(+3.64-7.45 \mathrm{~kJ} / \mathrm{mol})$ indicated spontaneous adsorption protocol favored by high adsorbate concentrations. The adsorption data simultaneous fitted the pseudo first order and pseudo second order kinetic models showing that film-diffusion and surface-chemisorption were the rate limiting steps. A part from the removal of $\mathrm{Pb}(\mathrm{II})(46 \%)$, which was considered low, the removal of metal ions including: $\mathrm{Cr}^{3+}(99-100 \%), \mathrm{Fe}^{3+}(96-98 \%), \mathrm{Mn}^{2+}(85-97 \%)$ and $\mathrm{Zn}^{2+}$ $(78-86 \%)$ from industrial wastewater based on this medium was well in excess of $80 \%$ range. These findings indicated that AlSiM could be utilized as an efficacious plausible and inexpensive adsorbent for treatment of metal-contaminated aqueous wastewater streams. Development of this technology for treatment of metal ion-polluted effluents would greatly reduce the cost of waste management in the related industries as the mineral media to be employed could be obtained cheaply and in large quantities from its natural deposits.

\section{REFERENCES}

1. Akcay, H.; Oguz, A.; Karapire, C. Study of heavy metal pollution and speciation in Buyak Menderes and Gediz river sediments. Water Res. 2003, 37, 813-822.

2. Koz, B.; Cevik, U.; Akbulut, S. Heavy metal analysis around Murgul (Artvin) copper mining area of Turkey using moss and soil. Ecol. Indic. 2012, 20, 17-23.

3. Manahan, S.E. Toxicological Chemistry and Biochemistry, 3rd ed., Lewi Publishers: London, England; 2003; p 233.

4. Areco, M.M.; Afonso, M.S. Copper, zinc, cadmium and lead biosorption by Gymnogongrus torulosus. Thermodynamics and kinetics studies. Colloids Surf. B: Biointerfaces 2010, 81, $620-628$.

5. Xiong, C.; Chen, X.; Yao, C. Study on the adsorption of $\mathrm{Pb}^{2+}$ from aqueous solution by D113-III resin. Desalin. Water Treat. 2012, 41, 62-71.

6. Ho, Y.S. Bibliometric analysis of biosorption technology in water treatment research from 1991 to 2004. Int. J. Environ. Pollut. 2008, 34, 1-13.

7. Wambu, E.W.; Onindo, C.O.; Ambusso, W.; Muthakia, G.K. Removal of fluoride from aqueous solutions by adsorption using a siliceous mineral of a Kenyan origin. CLEAN - Soil, Air, Water. 2013, 41, 340-348.

Bull. Chem. Soc. Ethiop. 2018, 32(1) 
8. Gupta, S.S.; Bhattacharyya, K.G. Kinetics of adsorption of metal ions on inorganic materials: A review. Adv. Colloid Interface Sci. 2011, 162, 39-58.

9. Ibrahim, H.S.; Jamil, T.S.; Hegazy, E.Z. Application of zeolite prepared from Egyptian kaolin for the removal of heavy metals: II. Isotherm models. J. Hazard. Mater. 2010, 182, 842-847.

10. Prasad, M.; Saxena, S.; Amritphale, S.S.; Chandra, N. Kinetics and isotherms for aqueous lead adsorption by natural minerals. Ind. Eng. Chem. Res. 2000, 39, 3034-3037.

11. Attahiru, S.; Shiundu, P.M.; Onyari, J.M.; Mathiu, E.M. Removal of Cu(II) from aqueous solution using a micaceous mineral of Kenyan origin. Adsorpt. Sci. Technol. 2003, 21, 269283.

12. Martínez, M.; Núriao, S.H.; Fiol, N.; Villaescusa, I.; Poch, J.; Miralles, N.; Hidalgo, S. Removal of lead(II) and cadmium(II) from aqueous solutions using grape stalk waste. $J$. Hazard. Mater. 2006, 133, 203-211.

13. Giles, C.H.; MacEwan, T.H.; Nakhwa, S.N.; Smith, D. Studies in adsorption. Part XI. A system of classification of solution adsorption isotherms, and its use in diagnosis of adsorption mechanisms and in measurement of specific surface areas of solids. J. Am. Chem. Soc. 1960, 786, 3973-3993.

14. El-Said, G.F.; Draz, S.E.O. Physicochemical and geochemical characteristics of raw marine sediment used in fluoride removal. J. Environ. Sci. Health. A. Tox. Hazard. Subst. Environ. Eng. 2010, 45, 1601-1615.

15. Weng, C. Modeling $\mathrm{Pb}(\mathrm{II})$ adsorption onto sandy loam soil. J. Colloid Interface Sci. 2004, 272, 262-270.

16. Weng, C.; Tsai, C.; Chu, S.; Sharma, Y.C. Adsorption characteristics of copper(II) onto spent activated clay. Sep. Pur. Technol. 2007, 54, 187-197.

17. Langmuir, I. The adsorption of gases on plane surfaces of glass, mica, and platinum. J. Am. Chem. Soc. 1918, 40, 1361-1403.

18. Maji, S.K.; Pal, A.; Pal, T. Arsenic removal from real-life groundwater by adsorption on laterite soil. J. Hazard. Mater. 2008, 151, 811-820.

19. Dubinin, M.M.; Radushkevich, L.V. The equation of the characteristic curve of the activated charcoal. Proc. Acad. Sci.U.S.S.R. Phys. Chem. Sect. 1947, 55, 327-331.

20. Polanyi, M. Adsorption from the point of view of the third law of thermodynamics. Verb. Deutsch. Phys. Ges. 1914, 16 1012-1016.

21. Andr, Y.; Le, P.; Reddad, Z.; Gérente, C.; Andrès, Y.; Thibault, J.F.; Le Cloirec, P. Cadmium and lead adsorption by a natural polysaccharide in MF membrane reactor: Experimental analysis and modelling. Water Res. 2003, 37, 3983-3991.

22. Puranik, P.R.; Paknikar, K.M. Biosorption of lead, cadmium, and zinc by Citrobacter Strain MCM B-181: Characterization studies. Biotechnol. Prog. 1999, 15, 228-237.

23. Parvathi, K.; Nagendran, R.; Kumar, R.N. Lead biosorption onto waste beer yeast byproduct, a means to decontaminate effluent generated from battery manufacturing industry. Electron. J. Biotechnol. 2007, 10, 92-105.

24. Ofomaja, A.E.; Unuabonah, E.I.; Oladoja, N.A. Bioresource Technology competitive modeling for the biosorptive removal of copper and lead ions from aqueous solution by Mansonia wood sawdust. Bioresour. Technol. 2010, 101, 3844-3852.

25. Ho, Y. Isotherms for the sorption of lead onto peat: Comparison of linear and non-linear methods. Polish J. Environ. Stud. 2006, 15, 81-86.

26. Vieira, D.M.; da Costa, A.C.A.; Henriques, C.A.; Cardoso, V.L.; de França, F.P. Biosorption of lead by the brown seaweed Sargassum filipendula - Batch and continuous pilot studies. Electron. J. Biotechnol. 2007, 10, 368-375.

27. Eba, F.; Biboutou, R.K.; Nlo, J.N.; Bibalou, Y.G.; Oyo, M. Lead removal in aqueous solution by activated carbons prepared from Cola edulis shell (Alocacée), Pentaclethra macrophylla husk (Mimosaceae) and Aucoumea klaineana sawdust (Burseraceae). Afr. J. 
Environ. Sci. Technol. 2011, 5, 197-204.

28. Payne, K.B.; Abdel-Fattah, T.M. Adsorption of divalent lead ions by zeolites and activated carbon: Effects of $\mathrm{pH}$, temperature, and ionic strength. J. Environ. Sci. Heal. Part AToxic/Hazard. Subst. Environ. Eng. 2004, A39, 2275-2291.

29. Tangjuank, S.; Insuk, N.' Tontrakoon, J.; Udeye, V. Adsorption of lead (II) and cadmium (II) ions from aqueous solutions by adsorption on activated carbon prepared from cashew nut shells. World Acad. Sci. Eng. Technol. 2009, 52, 110-116.

30. Gueu, S.; Yao, B.; Adouby, K.; Ado, G. Kinetics and thermodynamics study of lead adsorption on to activated carbons from coconut and seed hull of the palm tree. Int. J. Environ. Sci. Tech. 2007, 4, 11-17.

31. Badmus, M.A.O.; Audu, T.O.K.; Anyata, B.U. Removal of lead ion from industrial wastewaters by activated carbon prepared from periwinkle shells (Typanotonus fuscatus). Turkish J. Eng. Environ. Sci. 2007, 31, 251-263.

32. Rout, K.; Mohapatra, M.; Mohapatra, B.K.; Anand, S. Pb(II), Cd(II) and Zn(II) adsorption on low grade manganese ore. Int. J. Eng. Sci. Technol. 2009, 1, 106-122.

33. Chiron, N.; Guilet, R.; Deydier, E. Adsorption of $\mathrm{Cu}(\mathrm{II})$ and $\mathrm{Pb}(\mathrm{II})$ onto a grafted silica: Isotherms and kinetic models. Water Res. 2003, 37, 3079-3086.

34. Ayari, F.; Srasra, E.; Trabelsi-ayadi, M. Retention of lead from an aqueous solution by use of bentonite as adsorbent for reducing leaching from industrial effluents. Desalination 2007, 206, 270-278.

35. Yang, J.Y.; Yang, X.E.; He, Z.L.; Chen, G.C. Adsorption-desorption characteristics of lead in variable charge soils. J. Environ. Sci. Health Part A-Toxic/Hazard. Subs. Environ. Eng. 2004, 4529, 1949-1967.

36. Yin, Y.; Aroua, M.K.; Daud, W.M.A.W. Enhanced adsorption of metal ions onto polyethyleneimine-impregnated palm shell activated carbon: equilibrium studies. Water. Air. Soil Pollut. 2008, 192, 337-348.

37. Das, B.; Mondal, N.K. Calcareous soil as a new adsorbent to remove lead from aqueous solution: Equilibrium, kinetic and thermodynamic study. Univers. J. Environ. Res. Technol. 2011, 1, 515-530.

38. Shah, B.; Shah, A.; Tailor, R. Characterization of hydroxybenzoic acid chelating resins: Equilibrium, kinetics, and isotherm profiles for $\mathrm{Cd}(\mathrm{II})$ and $\mathrm{Pb}(\mathrm{II})$ uptake. J. Serbian Chem. Soc. 2011, 76, 903-922.

39. Ozacar, M.; S, engill, I.A.; Turkmenlerc, H. Equilibrium and kinetic data, and adsorption mechanism for adsorption of lead onto valonia tannin resin. Chem. Eng. J. 2008, 143, 32 42.

40. Ng, J.C.Y.; Cheung, W.H.; Mckay, G. Equilibrium studies for the sorption of lead from effluents using chitosan. Chemosphere 2003, 52, 1021-1030.

41. Dong, L.; Zhu, Z.; Ma, H.; Qiu, Y.; Zhao, J. Simultaneous adsorption of lead and cadmium on $\mathrm{MnO}_{2}$-loaded resin. J. Environ. Sci. 2010, 22, 225-229.

42. Zolgharnein, J.; Shahmoradi, A.; Ghasemi, J. Pesticides removal using conventional and low-cost adsorbents: A review. CLEAN - Soil, Air, Water. 2011, 39, 1105-1119.

43. Lagergren, S. Zur theorie der sogenannten adsorption gelöster stoffe. $K$. Sven. Vetenskapsakademiens. Handl. 1898, 24, 1-39.

44. Y. Ho, Pseudo-isotherms using a second order kinetic expression constant. Adsorption 2004, $10,151-158$.

45. Hefne, J.A.; Mekhemer, W.K.; Alandis, N.M.' Aldayel, O.A.; Alajyan, T. Kinetic and thermodynamic study of the adsorption of $\mathrm{Pb}$ (II) from aqueous solution to the natural and treated bentonite. Int. J. Phys. Sci. 2008, 3, 281-288.

46. Gupta, V.K.; Agarwal, S.; Saleh, T.A. Synthesis and characterization of alumina-coated carbon nanotubes and their application for lead removal. J. Hazard. Mater. 2011, 185, $17-$ 23. 